\title{
Os estudos de Antropologia no Museu Emílio Goeldi
}

\author{
Expedito Arnaud (")
}

\section{Resumo}

presente artigo mostra, em linhas gerais, os estudos de antropologia realizados no Museu Emílio Goel. di, principalmente após 1954, data em que passou a ser administrado pelo Instituto de Pesquisas da Ama. zônia. Contém os seguintes capitulos: 1) - Antecedentes históricos; 2) - A fase do INPA-MPEG; 3) - Os cbjetivos dos estudos; 4) - Os resultados alcançados: 5) - Os projetos em execução.

\section{ANTECEDENTES HISTÓRICOS}

A contribuição do Museu Goeldi nos estudos de antropologia, pode-se dizer que começa desde a criação da Associação Philomática (precursora do Museu), em 1866, através de seu primeiro diretor, o naturalista Domingos Ferreira Penna. A par das investigações realizadas sobre geografia, economia, agricultura e arqueologia, Ferreira Penna registrou aspectos interessantes sobre grupos indígenas e populações regionais, os quais divulgou pela Revista Amazônica e Archivos do Museu Nacional, nos seguintes artigos: "Comunicações antigas entre Matto Grosso e Pará; "Explorações no Amazonas e Rio Branco"; "Índios do Marajó"; "Algumas palavras da língua dos Aruás"; e "O Baixo Tocantins... os Anambés, sua história e seu caráter".

Com a reformulação do Museu, desenvolvida em 1894 por Emílio Goeldi, seu novo Diretor, o interesse pela antropologia foi incentivado embora fosse ele zoólogo. Assim, no relatório dirigido ao Governador Lauro Sodré (01/01/1896), ressaltou que $\mathbf{O}$ Museu Paraense não podia permanecer indiferente perante os problemas que agitam vivamente a atenção dos ethnologos; e prometeu participar activamente no movimento relativo a elucidação do aborigene amazonico. Ele próprio, escreveu um trabalho sobre "O estado actual dos conhecimentos sobre os índios do Brasil, especialmen- te na Amazonia"; e mostrou-se igualmente interessado em tornar conhecidos os objetos da natureza indigena. Desde então o pequeno acervo formado por cerca de 300 peças, começou a aumentar, através de doações e de aquisições de coleções famosas como as de Frei Gil de Vila Nova (índios Kayapó), Koch-Grünberg (grupos indígenas da área norte-amazônica) e José Júlio de Andrade (grupos africanos). Ainda na gestão de Goeldi, um outro zoólogo (Hermann Meerwarth), no trabalho sobre uma viagem de exploração ao rio Acará, apresentou informações sobre os índios Turiwára. Subseqüentemente, pela década de 1910, a zoóloga Emilie Snethlage, diretora do Museu, também realizou investigações entre grupos indígenas, havendo divulgado, em português e em alemão, um trabalho sobre os índios Xipaya e Kuruaya (Xingu-Iriri), incluindo um vocabulário comparativo dos dois dialetos.

Entre 1915 e 1921, o Museu principiou a entrar em decadência, devido a insuficiência de recursos, mas nesse período é que a etnologia começa a projetar-se em seu âmbito, com as pesquisas realizadas por Curt Nimuendaju, entre grupos tribais da Amazônia. De 1940 a 1945, quando faleceu, Nimuendaju novamente atuou no Museu (gestão de Carlos Estevão de Oliveira e Innocencio Machado Coelho), tendo sido então uma de suas monografias mais importantes (Os Apinayé) traduzida para o português por iniciativa de Carlos Estevão. Também confeccionou Nimuendaju um mapa de grandes proporções, mostrando as localizações remotas e as migrações dos grupos indígenas do Brasil; e ministrou três cursos de etnologia entre 1942 e 1943 . Mas como o Museu continuava em situação precária, um grupo de estudiosos formado por Armando Bordalo da Silva, Eurico Fernandes, Machado CoeIho (ainda Diretor do Museu), José Coutinho

( ${ }^{*}$ - Museu Paraense Emilio Goeldi, Belém. 
de Oliveira, Manuel Nunes Pereira e Paulo Ma. ranhão Filho, em 1947, fundou o Instituto de Antropologia e Etnologia do Pará, porém man. tendo vínculos com o Museu, em cujo recinto Ihe foi permitido atuar.

\section{A FASE DO CONVENIO INPA - MUSEU GOELDI}

Os estudos de antropologia voltaram a ser reativados, a partir de 1955 quando o $\mathrm{Mu}$ seu, já sob a administração do INPA admitiu como chefe da Divisão de Antropologia, o Dr. Eduardo Gaivão (Ph. em Antropologia pela Universidade de Colúmbia, EE.UU.). O trabalho começou a ser desenvolvido lentamente, face às dificuldades encontradas para atrair, de outros centros, antropólogos capacitados, que não desejavam naturalmente renunciar suas posiçōes para vir atuar na Amazônia, numa situação indefinida, apenas como bolsistas, que era, aliás, a enfrentada pelo próprio Galvão. Existiam, então, no quadro do Museu, Armando Bordalo da Silva (mais dedicado à antropologia física e ao folclore) e Peter Paul Hilbert (arqueólogo). Porém, em 1957, pôde Galvão atrair para a Divisão dois etnólogos - Carlos Moreira Neto, de formação acadêmica e cursos de aperfeiçoamento em antropologia; e Protásio Frikel, missionário franciscano, com larga experiência no assunto e com trabalhos publicados. Dai em diante, as pesquisas de campo começaram a ter curso regular; as coleçōes etnográficas passaram a aumentar sig. nificativamente; foram reiniciadas as publicaçōes; e um intercâmbio científico e cultural foi estabelecido com instituições nacionais e estrangeiras congêneres. Em 1960, Moreira Neto retornou ao sul do país mas, Edson Diniz (funcionário do Museu) inicia-se na carreira de pesquisador. Em 1962, foram admitidos mais três profissionais: Mário F. Simōes, Roberto Las Casas e Klass Woortmann. E, em 1963. ingressaram como bolsistas de aperfeiçoamen. to Conceição Corrêa e Expedito Arnaud. Nes sa fase, planejou Galvão editar uma "Suma Etnológica", sobre os grupos indígenas brasileiros, atualizando o que fora publicado pelo Handbook of South American Indians (Smithsonian Institution), em 1946 -1948; entretanto, o plano não chegou a ser levado a efeito, de- vido a falta de recursos para o financiamento das pesquisas e publicações.

Em novembro de 1963, Gaivão afastou-se do Museu e foi dirigir o Instituto de Ciências Humanas da Universidade de Brasília. A chefia da Divisão de Antropologia foi, então, assumida por Edson Diniz e, a partir de fevereiro de 1964, por Mário Simões, que logo estabeleceu um Curso de Aperfeiçoamento para estagiários. No início de 1965, Roberto Las Casas e Klass Woortmann deixaram de pertencer ao Museu - o primeiro foi lecionar em Brasília e o segundo na Universidade da Bahia. Mas, em fevereiro de 1966, Galvão retornou de Brasília e reassumiu a chefia da Divisão. Logo em seguida, tendo em vista a dinamização das pesquisas, iniciou estudos para a implantação de um Centro de Estudos Sócio-culturais da Amazônia, precedido por um Curso de Pesquisa Social. Este teve lugar no $2 .^{\circ}$ Semestre de 1968, em razão de um convênio firmado entre - Museu e a SUDAM (Superintendência do Desenvolvimento da Amazônia), que forneceu verbas para sua realização, sendo que, dentre os alunos que concluiram o curso, cinco foram admitidos como bolsistas na Divisão de Antropologia. Em 1969, a pesquisadora Adélia de Oliveira, recém admitida no Museu, obteve o grau de Doutor em Ciências pela Faculdade de

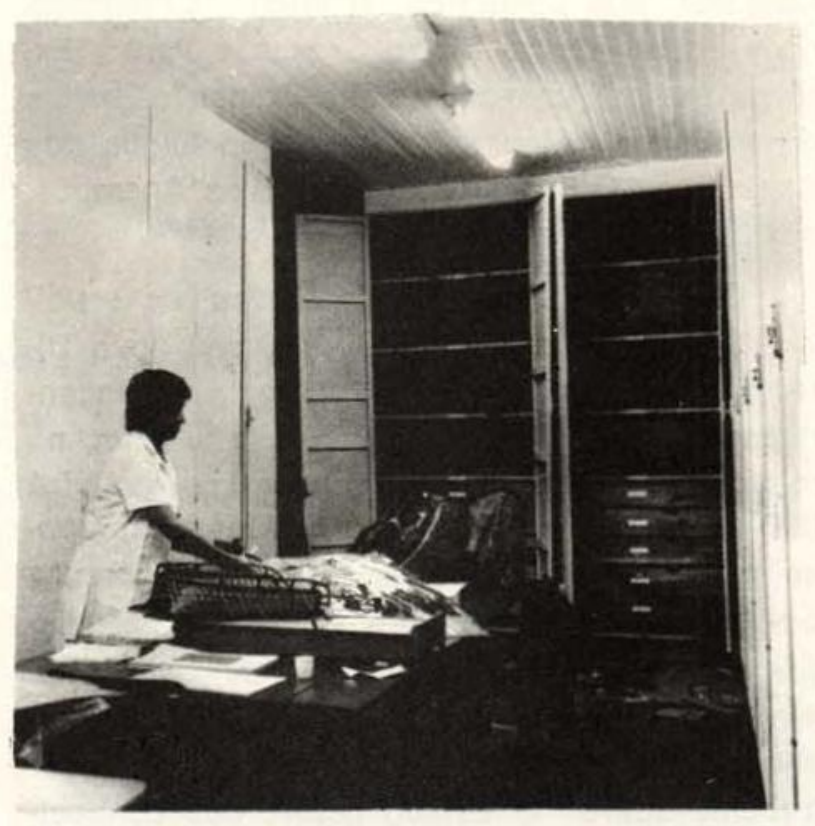

Fig. 1 - Setor de ergologia - Ivelise Rodrigues clas. sificando peças indigenas. 
Filosofia do Rio Claro (São Paulo) e Edson Diniz foi requisitado pela Faculdade de Filosofia de Marília (São Paulo) para lecionar na área de Ciências Humanas.

De 1970 a 1980, ocorreram, entre outros, os seguintes fatos: 1970 - Foi regulamentado na Divisão o "Estágio básico e de aperfeiçoamento em Antropologia”, o qual prosseguiu sem solução de continuidade. 1972 - Edson Diniz recebeu o grau de Doutor em Ciências na Faculdade de Filosofia do Rio Claro; e Lourdes Furtado realiza um estágio no Centro de Estudos de Antropologia Cultural do Museu de Etnologia do Ultramar (Lisboa). 1974 - Falece Protásio Frikel, deixando além de numerosas publicações, vários textos em elaboração. 1976 - A Divisão de Antropologia passa a ser constituída por duas Seções - Arqueologia e Antropologia Social - tendo sido a última inicialmente dirigida por Adélia de Oliveira Rodrigues e, em seguida, por Expedito Arnaud; Adélia de Oliveira Rodrigues, faz um estágio de pós-doutorado na Universidade de Oxford ("Senior Member do St. Antony's College"); e falece Eduardo Galvão, que se empenhava na revisão de seu antigo plano sobre a "Suma Etnológica". 1977 - Foi extinta a Divisão de Antropologia, tendo isso criado o Departamento de Arqueologia e o Departamento de Antropologia; este foi chefiado até 1979 por Expedito Arnaud, e desde então por Adélia de Oliveira Rodrigues, que prossegue dirigindo a Area de Antropologia, criada após o surgimento do Departamento de Ciências Humanas, em agosto de 1980. 1977-1980 - Concluiram o curso de mestrado em antropologia os seguintes pesquisadores do Departamento - Isidoro Alves e Roberto Cortez - Museu Nacional; Isolda da Silveira e Maria José Brabo - Universidade da Bahia; Ana Rita Alves (atualmente na Univ. Federal do Pará) na Universidade de Davis, Califórnia, EE.UU.; e Lourdes Furtado na Universidade de São Paulo. Prosseguiram realizando cursos do mesmo nível - Antonio Maria de Souza Santos - Universidade do R. G. Sul; Maria Helena Barata - Universidade de Brasília; Lúcia van Velthem e Antonio MagaIhães dos Santos - Universidade de São Paulo; e Isidoro Alves, inicia o doutorado no Museu Nacional.

\section{OS OBJETIVOS DOS ESTUDOS}

Desde a implantação da Divisão, os estudos relacionados às diversas áreas do conhecimento antropológico, sempre foram considerados no mesmo nível de interesse, sem distinção de escolas teóricas, não importando também que fossem ocorrer entre populações tribais, regionais ou urbanas desde que na região amazônica, face naturalmente à destinação atribuída ao próprio órgão. As linhas básicas estabelecidas para o desenvolvimento dos projetos foram as seguintes: 1) Estudo das áreas indígenas e regionais, tendo em vista a análise de seus elementos culturais, sociais e econômicos; 2) Análise das mudanças sofridas, pelos grupos indígenas face ao envolvimento e contato com a sociedade nacional; 3) estudos de comunidades regionais em contato com grupos indígenas, a fim de conhecer pelo menos as diretrizes culturais dessas comunidades, fatores de acionamento de mudanças nas sociedades tribais; 4) conhecimento da política indigenista - ação oficial e missionária; 5) estudos de línguas indígenas e dialetos regionais; 6) estudos etno-museológicos; 7) estudos de comunidades rurais e urbanas: situação gerais e específicas; 8 ) realização de cursos e estágios de aperfeiçoamento para universitários e graduados dos cursos de ciências humanas, no sentido de encaminhá-los para a carreira de antropologia.

\section{OS RESULTADOS ALCANÇADOS}

Entre 1955 e 1980, os resultados alcançados pelos antropólogos do Museu, em decorrência dos trabalhos efetuados, podem ser assim evidenciados:

\section{PESQUISA DE CAMPO}

Áreas indígenas - Foram realizadas 77 excursões, em 6 áreas da Amazônia Legal; tendo sido investigados 41 grupos indígenas distintos, a saber: Area Norte-Amazônica-Uaçá, Oiapoque, T. Amapá - índios Palikur, Galibí e Karipuna: Expedito Arnaud - 7 (1964, 1965, 1966, 1968, 1973 e 1978); Indios Oyampik e Emerilon: Expedito Arnaud - 1 (1966). Tumu- 
cumaque-Paru de Oeste, Pará, índios Tiriyó, Ewrahoyána e Kaxuyána: Protásio Frikel - 11 (1959, 1960, 1961, 1963, 1965, 1966, 1968 1969, 1970, 1971 e 1972); Ruth Wallace - 3 (1966, 1968, 1969); Roberto Cortez - 2 (1971 e 1975) Paru de Leste-Jari, Pará, indios Wayana-Aparaí: Protásio Frikel - 1 (1955-56), Lúcia van Velthem - 3 (1975, 1977 e 1978). Indios Waiăpl (Oyampik) - Lúcla van Velthem - 1 (1980). Rio Branco-Araricoera, Roraima. Indios Makuxí e Wapixana: Edson Diniz - 4 (1964, 1965. 1966 e 1967). Rio Catrimani, Roraima. Indios Yanomani (Waykã): Edson Diniz - 1 (1967-68) Alto rio Negro, Amazonas. Indios Baniwa, Tukano, Kobewa, Maku: Eduardo Galvão - 1 (1955), Adélia de Oliveira - 1 (1971), Antonio Maria dos Santos - 2 (1976 e 1980). Médio Solimões, Amazonas. Indios Mirânia: Expedito Arnaud - 1 (1974). Tocantins-Xingu - Médio Tocantins, Pará. Indios Akuawa-Asurini. Parakanan e Gaviōes de Oeste (Parkateyê):
Expedito Arnaud - 8 (1961, 1962, 1967, 1970 , 1971, 1972, 1975 e 1977). Itacaúnas-Caeteté, Pará. f́ndios Kayapó-Xikrin: Protásio Frikel -2 (1962 e 1963). Rio Fresco-Xingu, Pará. Indlos Gorotire e Kubén-Kran-Kegn (Kayapó): Edson Diniz - 3 (1961 e 1962). Grajaú-Pindaré, Mo. ranhão. Indios Krikati e Pukopüo (Pukobyé): Edson Diniz - 2 (1969), Maria Helena Barata - 1 (1980). Barra do Corda, Maranhằo, Indios Ramkokamekra-Canela: Expedito Arnaud - 1 (1979). Tapajós-Madeira: Adélia de Oliveira com Ivelise Rodrigues - 3 (1973, 1975 e 1976). Rio Cururu-Tapajós, Pará. Indios Mundurukú: Protásio Frikel - 2 (1957 e 1973), Lúcia van Velthem - 2 (1973 e 1974). Alto Xingu - Rio Xingu e afluentes, Mato Grosso. Indios Juruna, Kamayurá, Kayabí, Aueté, Mehinaku, Waurá, Yawalapiti, Kalapalo, Bakairi, Kuikuru, Txicăo, Suyá: Eduardo Galvão - 6 (1964-3, 1965-2 e 1966), Mário Simōes - 1 (1963), Adélia de Ollveira -3 (1965, 1966 e 1967), Protásio Frikel

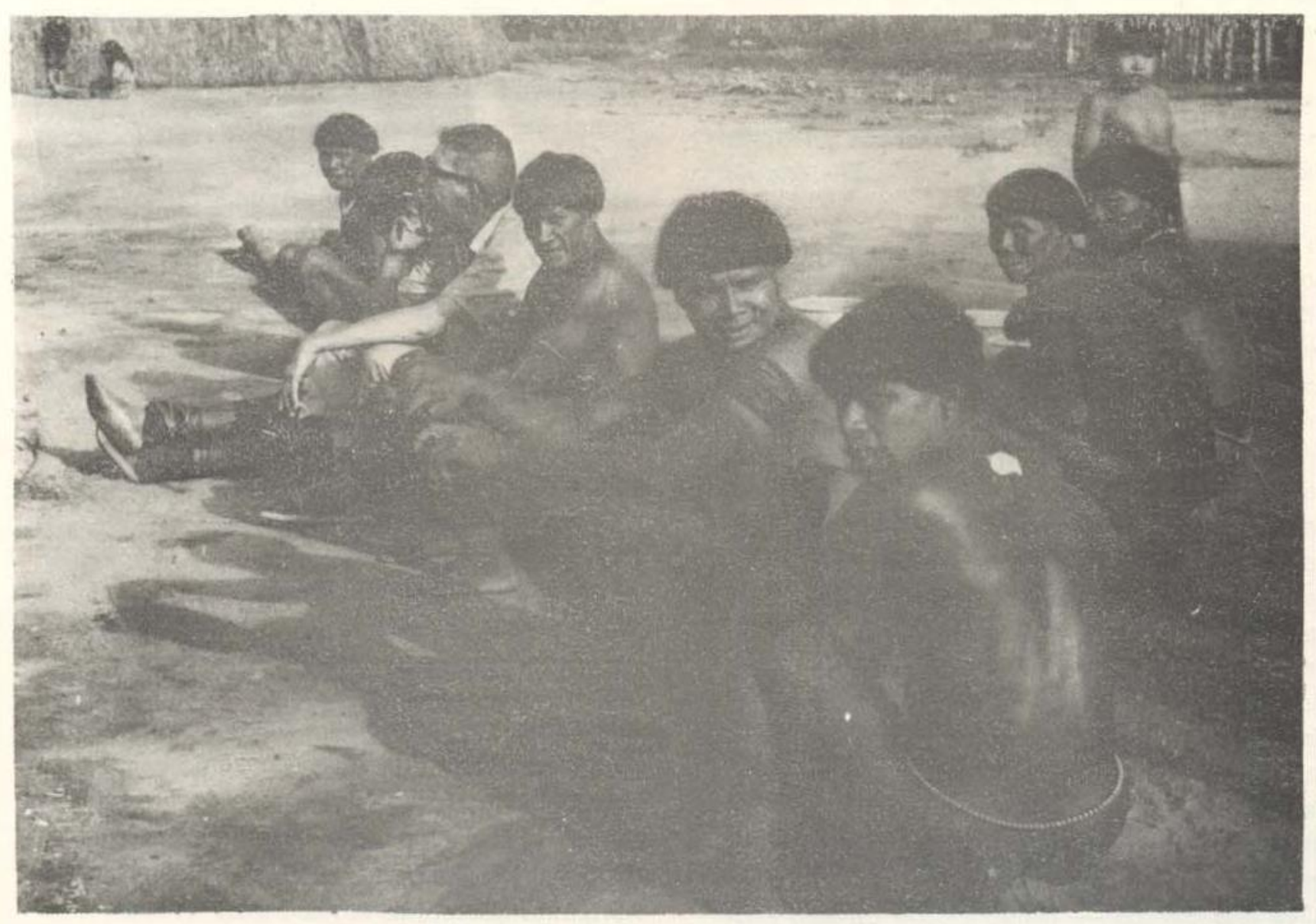

Fig. 2 - Pesquisa de campo - Alto Xingu (Mato Grosso) - Eduardo Galvăo entre os indios Kamayura. 
-2 (1966 e 1967). Pindaré-Gurupi - Rio Caiari-Moju, Pará. Indios Anambé: Eduardo Galvão e Expedito Arnaud - 1 (1969); Rio Guamá, Pará. Indios Tembé: Expedito Arnaud - 1 (1980).

Areas Regionais - Foram efetuadas 45 excursōes nas seguintes áreas: Médio Amazonas Paraense - Santarém: Isidoro Alves - $\mathbf{5}$ (1977, 1978 e 1979), Antonio Maria de Souza Santos - 6 (1977-3 e 1978-3). Oriximiná: Eduardo Galvão - 1 (1967); Isolda da Silveira - 2 (1969). Campos do Marajó, Pará - Muaná - Maria José Brabo - 3 (1975, 1976 e 1977). Cachoeira do Arari - Maria José Brabo - 1 (1978). Marabá, Pará - Itupiranga: Expedito Arnaud - 3 (1967, 1970 e 1972); Ana Rita Alves - 1 (1974). Conceição do Araguaia, Pará - Pau d'Arco: Carlos Moreira Neto - 2 (1957 e 1958). Tomé-Açu, Pará - Tomé-Açu: Isolda da Silveira - 2 (1979 e 1980). Salgado, Pará - Marapanim: Lourdes Furtado - 7 (1972. 1973, 1975, 1976, 1977, 1978 e 1979). Primavera: Isolda da Silveira -4 (1972, 1973, 1976 e 1977). Bragantina, Pará - Benevides: Maria José Brabo - 2 (1971 e 1973). Igarapé-Açu: Lourdes Furtado - 1 (1980), Arian Nery - 1 (1980). Rio Negro, Amazonas - São João-Sta. Isabel, (Tapuruquara): Eduardo Galvão e Adélia de Oliveira - 1 (1972). Médio Solimões, Amazonas - Tefé-Alvarães: Expedito Arnaud - 1 (1974). Norte Matogrossense - Aripuanã: Expedito Arnaud, Roberto Cortez e Lúcia van Velthem - 1 (1975). Cametá: Adélia de Oiiveira -1 (1974).

\section{PUBLICAÇõES}

A primeira publicação de etnologia do Museu, após o início do convênio INPA-MPEG foi a monografia de Nimuendaju - Os Apinayé, em 1956, cuja tradução, como vimos, ocorreu na gestão de Carlos Estevão. De 1959 a 1980 . os pesquisadores atuantes na área em ques. tão, publicaram 131 trabalhos, (salvo omissão) sem contar os resumos de comunicações enviados a congressos e os artigos divulgados em jornais. Através do Museu foram publicados 60 no Boletim, $n$. série, Antrop. e 12 nas Publicações Avulsas, 48 por intermédio de re- vistas especializadas ou de outras edições nacionais; e 11 o foram em edições estrangeiras.

Com respeito aos trabalhos sobre populações indígenas, de cunho mais específico, apresentamos os seguintes:

Cerimonial - Indios Tiriyó. Cortez (1975) - Procura "articular o mito sobre a origem da mulher com uma instituição (o diálogo cerimonial)". Figueiredo (1961) - Aramagoto - Descreve a "festa dos coletores" - uma manifestação grupal para comemorar a "coleta" realizada nos períodos em que há fartura e abun. dância de alimentação. Frikel (1961) — Kaxuyána - "Festa do Rapé" — paricá - Cerimônia relacionada com alguns antigos costumes guerreiros e crenças religiosas;

Demografia - Frikel \& Cortez (1972): Evarhoyána - Tiriyó - Faixas etárias, mulheres prolificas, concepçōes, abortos e natimortos, mortalidade e genealogia; apêndice: 1) parentesco classificatório Tiriyó e tipos de casamento; 2) casos de possível esterilidade.

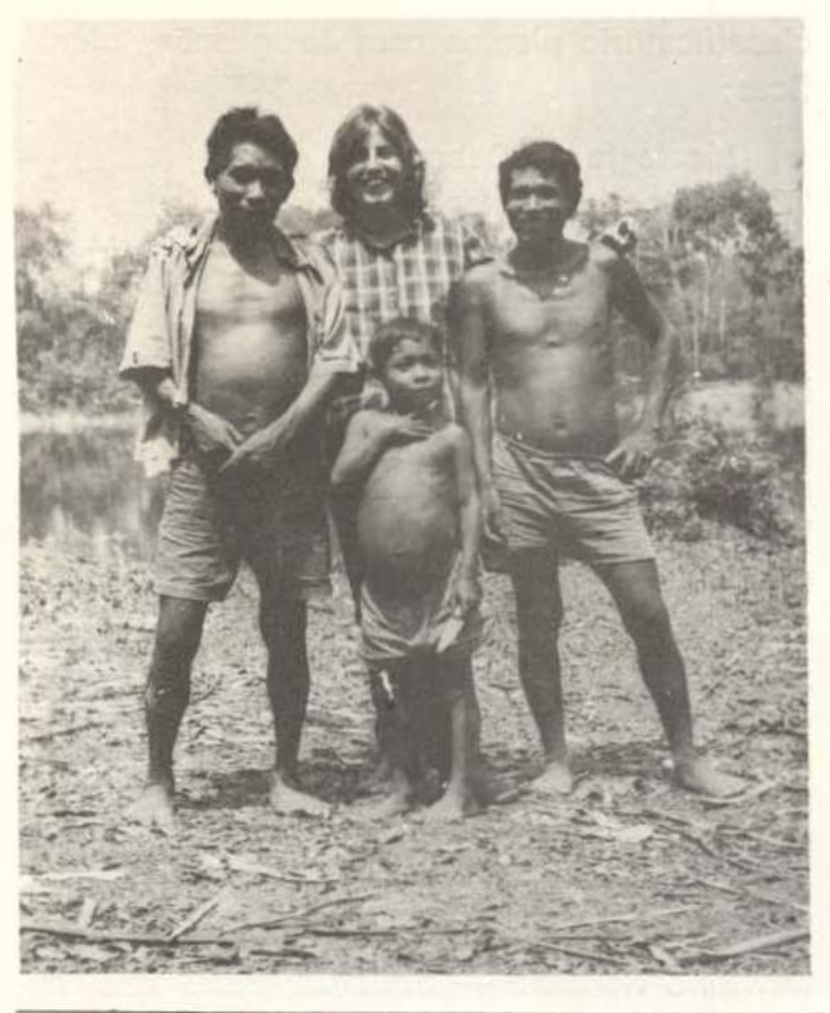

Fig. 3 - Pesquisa de campo - rio Madeira (Amazonas) - Adélia de Oliveira entre os índios Mura-Pirahă. 
Galvão \& Simões (1972) - índios do Alto Xingu - Kalapalo, Kuikuro, Nahuquá, Mati, Waurá, Mehináku, Yawalapiti, Kamayurá, Aweti e Trumái - Aspectos demográficos obtidos em 1952 e 1963, comparados com dados registrados por Meyer e von den Stein em fins do século XIX. Oliveira \& Salzano (1969) - Juruna Implicações sobre a demografia (1842 a 1967), comparando-a com a de outros grupos indígenas: Xavante, Bororo, Caingang, Yanomano;

Ergologia - Frikel (1968) - Xikrin-Kayapó - Equipamento material, armas, materiais de fixação, cestaria, utensílios, cachimbos, fusos, instrumentos de pintura, brinquedos, indumentária, adornos, economia tribal e vários aspectos a mesma relacionados. Rodrigues \& Oliveira (1977) - Mura-Pirahã - Adornos brinquedos, transportes e subsistência; lista descritiva artefatos indígenas. Velthem (1975) Tukano - coleções de plumárias vistas segundo "critérios museográficos";

Farmacopéia - Cavalcante \& Frikel (1973) - Tiriyó - "Terminologia medicinal", aplicação remédios, índice etno-botânico; quadro classificatório plantas com designações científicas;

Ideologia - Desana - Alves (1978) "Exercício de avaliação" das entidades que servem de mediadoras na cosmologia". Arnaud (1970) Palikur-Galibi-Karipúna - Crenças tradicionais e influência cristã; xamanismo tribal - Frikel (1961b) - Tiriyó - Interpretação de lendas sobre a transformação em pedras de antepassados míticos. Velthem (1976) Wayana-Aparaí - "Figuras colhidas da narrativa mítica num constante processo de atua. lização e uma forma de tornar real seres não reais";

Lingüística - Migliazza (1965a) - Makú - Esboço sintático - fonema, sílaba e palavras fonológicas; id. (1965b) - Tiriyó - fonemas, sílabas, vocabulários, grupos de entonação e grupo de pausa; id. (1967) - Grupos território Roraima - Situação atual das línguas. Wallace (1970) - Kaxuyána - Fonema, sílaba, vocábulo fonológico e grupos de entonação;
Etnohistória - Frikel (1970) - Kaxuyána - Origem e migrações desde os tempos mitológicos; Apêndice: Reminiscências andinas e Circum-Karib, migrações século XVII, denominações geográficas e etnográficas, transcrição Kaxuyána. Id. (1969-72) — Suyá - "Migração, guerra e sobrevivência";

Parentesco - Arnaud (1963) - AkuawaAsurini - Família, casamento, terminologia (tipo Sudanês); Id. (1968) - Galibí - Casamento, descendência, residência, terminologia (tipo Iroquês); Ibid. Palikur - Descendência, residência, sistema clânico, casamento, família, terminologia (tipo iroquês); Arnaud \& Alves (1975) - Galibi e outros grupos Karib-Kalina, Barama, Trió, Makuxi e Kuikúru - Análise comparativa das terminologias; Arnaud et al. (1976) - Gaviões de Oeste (Parkateyê) - Casamento, residência, terminologia (tipo Crow). Diniz (1965) - Makuxi - Descendência, residência, casamento e família, terminologia (tipo Iroquês); Id. (1968) - Wapitxána - Terminologia (tipo Iroquês). Oliveira (1970a) - Juruna Terminologia tipo Iroquês), casamento, residência, constituição da família, dados demográficos. Id. (1975a) - Baníwa - Organização social e política e terminologia do parentesco (provavelmente tipo Sudanês). Id. (1978) Mura-Pirahã - "Sistema de duas seções", parecendo ser a terminologia "consideravelmente mais simples do que as demais conhecidas grupos das Américas e da Amazônia em particular";

Política Indigenista - Arnaud (1969) Índios do Uaçá (Palikur-Galibi-Karipuna) — Programas postos em prática pelo S.P.I. (19301967) e seus resultados. Id. (1971) — Indios do Sul do Pará - Situações ocorridas após terem sido eles pacificados pelo S.P.I. Id. (1973) - Legislação indígena - Desde a época colonial até o atual Estatuto dos índios, no referido ano ainda em tramitação no Congresso Nacional. Id. (1975a) - Indios Mund.ırukú Ação desenvolvida pelo S.P.I. (1941-1964) no sentido neutralizar o monopólio exercido sobre a produção de borracha desses índios por duas agências - Alto Tapajós e Missão do Rio Cururu. Moreira Neto (1959) - Índios Kayapó Conseqüências ocorridas face a ação protecio- 
nista do S.P.I. a qual considera semelhante "as técnicas coloniais de descimento e aldeamento compulsório de grupos tribais". Oliveira (1976) - Indios da Amazônia. A política indigenista considera "inoperante e dissociativa", tal como nos três primeiros séculos de ocupação e colonização. Velthem (1980) - indios Parque Tumucumaque - Sugestões no sentido de ser modificado os atuais limites do Parque, por não atenderem "a real ocupação indígena da região";

Subsistência - Frikel (1959) - Mundurukú - Agricultura, técnicas aplicadas, divisão de trabalho, propriedade, auxílio mútuo, migrações, glossário termos plantas cultivadas e roças. Galvão (1963) - Indios do Brasil - plantas cultivadas, áreas de cultivo preferencial, técnicas, instrumental, tamanho, forma das roças e processamento dos produtos.

\section{* * *}

Entre as publicações de caráter mais generalizado (excluindo as notícias preliminares) ou de feição monográfica apreciamos as seguintes: Arnaud (1975) — Indios Gaviōes de Oeste - Aborda os contatos havidos entre os Gaviōes e a sociedade nacional - frentes deexpansão, núcleos regionais, administraçōes oficiais e missionárias através dos seguintes capítulos - A Região do médio Tocantins 2) Os Gaviões - caracterização sócio-cultural; 3) Os conflitos; 4) Os grupos-locais após a pacificação. Em instância final apresenta recomendaçōes no sentido de os Gaviōes serem conduzidos "para uma integração mais harmônica no seio da sociedade nacional". Cortez (1977) - Tiriyó-Ewarhoyana - Refere uma determinada modalidade de contato inter-étnico entre "indios e brancos" no Parque Tumucumaque. O processo é mostrado como essencialmente condicionado pela presença da ação missionária sendo caracterizado no nível econômico por dependência, no político por sujeição-dominação e no social por ideologia igua litária. Diniz (1972) — Os Makuxí - sua instalação na sociedade nacional. Procura mostrar "através de um estudo de caso" o processo de interação entre índios e brasileiros numa zona pastoril do extremo norte do Brasil, na seguinte seqüência: 1) $O$ cenário regional; 2) a sociedade Makuxí; 3) a situação de contato. Em conclusão diz que a sociedade Makuxí apresenta-se em uma situação de instabilidade em razão da perda da autonomia, invasão do seu território e dependência econômica. Fríkel (1971) - Dez anos de aculturação Tíriyó (1960-70) - Processo verificado em decorrência dos contatos com a "civilização moderna" representada no Brasil pelo "Trinômio FAB. Missionário e no Suriname pelas Missões Protestantes. Ocorreu nos seguintes aspectos demografia, nacionalidade, língua, cultura material, indumentária, saúde, ideologia, organização social e economia. Na conclusão, salienta que a influência católica verificou-se mais na cultura material e a protestante na ideologia. Id. (1973) - Os Tiriyó: sistema adaptativo - Descreve o equipamento doméstico, habitaçōes, armas, utensílios, cerâmica, brinquedos, música e instrumentos, venenos, estimulantes, ciclos de trabalho. A situação cultural é apreciada através de quatro fases - a primitiva pré-ceramista, a arcaica, a histórica e a atual (século $X X$ ). Apêndices - 1)

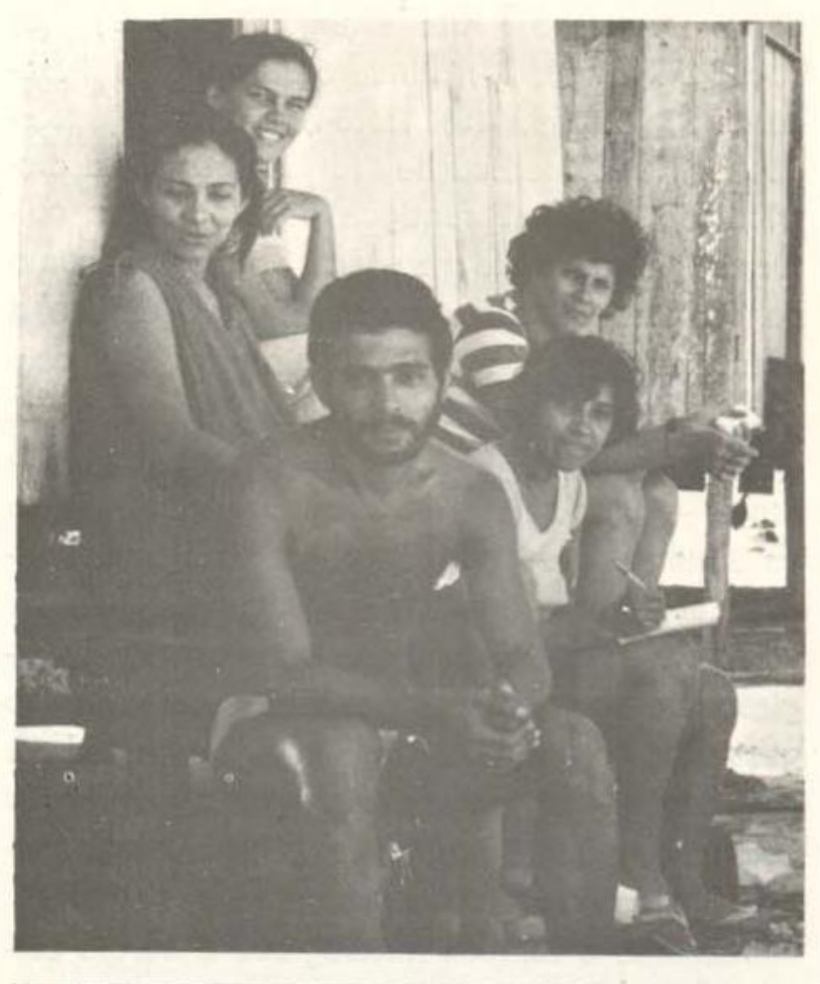

Fig. 4 - Pesquisa de campo - Região do Salgado (Pa. rá) - Lourdes Furtado e auxiliares. 
termos da ergologia, 2) plantas cultivadas, 3) plantas apreciadas, mas não cultivadas, e 4) plantas silvestres utilizadas. Galvão (1959) Aculturação indígena no rio Negro - índios Kobewa, Tukano, Maku e Baníwa - O autor se interessa mais pelo processo de modificação dessas culturas e de sua integração na sociedade regional que na reconstituição etnológica de culturas tribais. Na parte final, diz que a ativa participação do indio na vida econômica local, parecia favorecer a assimilação dos grupos pela sociedade nacional; todavia, o processo poderia sofrer um retardamento e mesmo interrupção com a abertura de novas frentes de colonização e introdução de técnicas de caráter industrial, provocando a retração dos grupos indigenas para as malocas. Id. (1960) Áreas culturais indígenas do Brasil, (1900-59). Id. (1960) - Áreas culturais indígenas do Brasil, (1900-1959) - Trabalho baseado no conceito de área cultural, desenvolvido principalmente por antropólogos norte-americanos. Foram identificadas 11 áreas culturais distintas: 1) Norte-Amazônica - (núcleos A-B-C), 2) JuruáPurus, 3) Guaporé (A, B, C), 4) Tapajós-Madeira $(A-B), 5)$ Alto Xingu $(A-B-C), 6)$ Tocantins-Xingu, 7) Pindaré-Gurupí, 8) Paraguai, 9) Paraná, 10) Tieté-Uruguai, 11) Nordeste. Na classificação foi enfatizada a distribuição espacial contígua de elementos culturais, tanto os de natureza ergológica como os de caráter sócio-cultural, considerando a aculturação inter-tribal, os contatos e o contexto cultural das frentes pioneiras nacionais. Oliveira (1970b) - Os indios Juruna do Alto Xingu - Estuda as relações inter-tribais entre os Jurunas e os outros grupos indígenas, porém, com mais interesse o autor fixou-se na visão da atual sociedade e cultura Juruna, registrando tanto quanto possível a situação do passado. O trabalho apresenta os seguintes aspectos - Migrações, demografia, cultura e sociedade, aldeias, economia, organização social, chefia, ciclo de vida, práticas religiosas, xamanismo e tempos mitológicos e heróis culturais. Por fim é salientado que o processo de aculturação dos Juruna iniciada desde os primeiros contatos com europeus e luso-brasilei- ros, parecia irreversivel, embora as condições oferecidas pelo Parque Nacional do Xingu, pudessem permitir um "revivalismo" da tradição tribal.

Entre as publicações a respeito de populações regionais, as de maior amplitude e que tomaram uma feição definitiva, apresentamos a seguir: Brabo (1979) — Os roceiros de Muaná - Discute a forma pela qual ocorre a participação dos roceiros no interior do sistema e da sociedade mais ampla. A primeira parte mostra a organização econômica do município; e a segunda refere-se à economia dos povoamentos Atuá e Mocajatuba, procurando estabelecer semelhanças e contrastes entre os dois subsistemas. Furtado (1980) - Curralistas e redeiros de Marudá - (Marapanim) - Estudo sobre a vida da organização da produção e de suas relações de mercado e as transformações provocadas pela expansão urbana e capitalista. Nas considerações finais apresenta uma caracterização de economia dos pescadores, segundo o conceito de economia camponesa adotado por Firth (1974). Moreira Neto (1969) a cultura pastoril do Pau d'Arco - Araguaia Formação e desenvolvimento da onda pastoril a partir do fim do século $\mathrm{XIX}$, numa região tradicionalmente ocupada pelos índios Kayapó, apreciada na seguinte seqüência - Or'gens, formas de ocupação, organização de produção, grupos e instituições sociais, ideologia e mudança cultural. Oliveira (1972) - São João Povoado do Rio Negro Histórico da colonização da área, atividades econômicas. O relacionamento social, estratificação, ensino e comunicação, manifestações relogiosas. Por fim, discute a possibilidade dos habitantes do povoado serem enquadrados dentro das características do campesinato. Silva (1959) - Folclore da zona Bragantina - Distingue cinco micro áreas ecológicas: área marítima ou da pesca, área dos campos, pecuária e tabaco, área da fibra e área da farinha e cereais. Em seguida descreve os festivais populares, cujas manifestações são mostradas em suas familiaridades com os de outras áreas da região amazônica. Silveira (1979): Quatipuru (Primavera): Focaliza o sistema econômico local baseado na coivara e em atividades de pesca e coleta, 
ca e histórica da micro-região do Salgado (Pará). Conclui dizendo que, entre as três categorias ocupacionais, a do lavrador é a mais auto-suficiente de todas, pois, tanto o pescador como o coletor dependem dos produtos agricolas para atender as necessidades da dieta.

Quanto a publicações sobre populações urbanas, aplicando o mesmo critério anterior. evidenciamos a seguinte: Alves (1980) - O Carnaval devoto - Descrição analítica dos diversos momentos da Festa de Nazaré, com ênfase primordial para seu evento mais importante, o Círio. Em conclusão salienta que, ao nível da representação dramática, a festa e em especial, o Cirio, são bem a expressão de uma sociedade que só aparentemente está em equilibrio. No contexto do ritual o equilíbrio é dado de um lado, pelo poder aglutinador da Santa e, de outro pela convergência das diferentes ordens de valores apontadas para um mesmo espaço e tempo.

\section{ETNOMUSEOLOGIA}

Em 1921, Nimuendaju confeccionou o primeiro catálogo das peças existentes num total de 2.729 , além de várias outras de procedência duvidosa; em 1946, um outro catálogo foi feito por Evalda Xavier Falcão (Naturalista Classe L); e, em 1955, Galvão estabeleceu um novo tipo de catálogo, mantendo no verso de cada folha a antiga numeração, e, com Peter Hilbert (arqueólogo), procedeu o tombamento do acervo existente. Em 1956, quando um prédio foi construído para o depósito das coleções, verificou-se uma reforma geral da exposição permanente: o material da exposiçăo foi reduzido, a fim de serem melhor atendidos os problemas de ordem científica e didática; e o caráter regional do Museu foi reforçado, tendo sido, por isso, recolhidas as peças que não eram da área amazônica. Em 1962, escreveu Galvão o Guia n\% 1 - Exposição de Antropologia, atualmente na 4.' edição. Em 1963, o material existente no depósito foi acondicionado em novos armários, segundo a classificação de Galvão - (1960) - “Áreas culturais indígenas do Brasil (1900-1959)"; e a partir do início de 1964 de acordo com uma codificação e classifica- ção padronizadas por Mário Simões, foi iniciado o fichamento das armas, bancos e objetos de cerâmica.

Em 1966, por ocasião do $10^{\circ}$ Centenário do Museu, uma nova reforma foi feita na exposição, sendo porém, mantida a estrutura da anterior, e em 1977, em um novo prédio (Pavilhão Eduardo Galvão), foi organizada uma outra exposição e uma parte das coleções foi removida para outro depósito. Em 1980, por ocasiāo da Semana do índio (abril) foi organizada uma exposição temporária sob o tema "A luta do índio", e em outubro e novembro do mesmo ano sob os auspícios do Museu de Arte Moderna de São Paulo, verificou-se uma exposição de arte plumária com a participaçăo nos trabalhos de dois profissionais do Museu - Lúcia van Velthem e João Carlos Rodrigues.

De 1956 a 1980, o acervo etnográfico foi acréscido de 6.135 peças, destacando-se pelo número de variedade as coleções de Protásio Frikel - índios Tiriyó e Kayapó-Xikrin com 991 e 633 peças, respectivamente; e a de William Crocker - índios RamkokomekraCanelas - com 733. Presentemente, existe um total de 13.125 peças assim distribuídas: Indígenas - Área Norte Amazonica: 3.560, Juruá-Purus - 160, Guaporé - 77, Tapajós-Madeira: 415, Alto Xingu: 910, Tocantins-Xingu: 6.085, Pindaré-Gurupi: 453, Paraná: 8 , Nordeste: 137, total 11.805; Material Africano - 593 peças; populações regionais: 86 ; outras procedências: 641 . Um documentário a respeito das referidas coleções e as da Universidade Federal do Pará (Depart. Antropologia) foi publicado por Figueiredo \& Rodrigues (1973).

\section{ENSINO E ORIENTAÇÃO}

A partir do início da década de 1960 passou a Divisão de Antropologia também a atuar nas áreas de ensino e orientação através de cursos, estágios, supervisão e/ou assessoramento. No próprio âmbito do Museu há para mencionar o seguinte: 1961 - Curso de extensão universitária de etnologia e arqueologia da Amazônia-Museu-Faculdade Filosofia Univ. Pará. Professores: Eduardo Galvão, Protásio Frikel, Napoleão Figueiredo, Edson Diniz e Fre- 
derico Barata. 1964 - Curso de antropologia para estagiários - Básico, Aperfeiçoamento e Especialização - Coordenador Mário Simões: - Professores: Eduardo Galvão, Edson Diniz, Cleber Alho, Isolda Albuquerque, Klass Woortmann, Mário Simões, Napoleão Figueiredo e Roberto Las Casas. 1968 - Curso de Pesquisa Social - Coordenadores: Eduardo Galvão e Oracy Nogueira. Professores: Aparecida Gouveia, Eva Blay, Cândido Procópio Camargo, George Fukui, Léa Rocha, Lia Fukui, Juarez Lopes, Mário Carneiro Leão, Mário Wagner, May Souza Rubião, Oracy Nogueira, Paulo Sandroni e Paulo Singer. Foram inscritos 42 alınos havendo 30 concluído o curso. Além de bolsistas do Museu participaram do curso professores universitários e funcionários de nível superior de diversas instituições ligadas ao desenvolvimento da Amazônia. 1970 e ss. - Estágio Básico e de aperfeiçoamento em Antropologia - Formação teórica e atividades de pesquisa - para universitários e graduados em Ciências humanas. Coordenadores até 1980 - Eduardo Galvão, Samuel Sá, Expedito Arnaud, Adélia de Oliveira Rodrigues, Roberto Cortez e Isidoro Alves.

A participação de pesquisadores da Divisão de Antropologia em cursos e programas realizados por outras instituições assim se verificou: $1968-1 .^{\circ}$ Curso de Aculturação da Amazônia - Conferência Nacional dos Bispos (CNBB) - Coordenador Samuel Sá - Professores do Museu, Adélia de Oliveira, Eduardo Galvão, Protásio Frikel e Expedito Arnaud. 1970-71 - Grupo de trabalho GT - FUNAI: Transamazônica - Planejamento e orientação da ação indigenista - Coordenador Eduardo Galvão: Membros Adélia de Oliveira, Expedito Arnaud, Protásio Frikel, Abel Tenório (SESP), Smith do Amaral (DNER), Fernando Bahia e Antonio Nogueira (FUNAI). $1972-2{ }^{\circ}$ Curso de Aculturação da Amazônia - CNBB - Coordenador Samuel Sá - Professores do Museu Adélia de Oliveira, Eduardo Galvão, Protásio Frikel e Expedito Arnaud. 1975-1980 - Cursos de Desenvolvimento de Comunidades SUDAM - Professores do Museu Adélia de Oliveira Rodrigues (1974, 1975, 1976, 1978 e 1979), Lourdes Furtado (1973, 1979, 1980), Ro- berto Cortez (1974), Isidoro Alves (1977). 1975 - Curso extensão universitária - Faculdade Filosofia - Recife - Indios do Brasil. Professor - Adélia de Oliveira Rodrigues. 1978-79 - Curso nível pós-graduação NAEA - Universidade Pará. Professor do Museu - Isidoro Alves. 1977 - Curso de Indigenismo - Conselho Indigenista Missionário (CIMI) - Professor do Museu - Expedito Arnaud. 1980 1. Curso de Atualização em Sociologia - Ass. Regional Sociólogos - Professor do Museu Roberto Cortez.

\section{PROJETOS EM ANDAMENTO}

Em fins de 1980, encontravam-se em andamento os trabalhos relacionados ao projeto Estudos de Antropologia na Amazônia, compreedendo quatro áreas $(1-\mathrm{O}$ índio e a sociedade nacional na Amazônia, 2 - Etnologia dos grupos indígenas, 3-Campesinato na Amazônia e 4 - Treinamento aperfeiçoamento e formação de pessoal), e dividido entre os 13 subprojetos seguintes: 1) Índios e agentes da sociedade nacional - Responsável - Adélia de Oliveira Rodrigues; 2) $\mathrm{O}$ índio e a expansão nacional; Responsável - Expedito Arnaud; 3) Estudos de situações de contato interétnico - Responsável - Roberto Cortez; 4) Parakanã - Transferência das comunidades indígenas - Responsável - Antonio Carlos Magalhães; 5) Os Pukobyé e a expansão nacional - Responsável - Maria Helena Barata; 6) Os índios do alto rio Negro e os agentes de contato - Responsável - Antonio Maria dos Santos; 7) Wayana-Aparaí - Responsável Lúcia van Velthem; 8) Estudo sobre a ergologia indígena - Responsável - Ivelise Rodrigues; 9) Santarém-Campesinato, patronagem e mudança social - Responsável - Isidoro Alves; 10) Campos de Marajó - Aspectos gerais do campesinato - Responsável - Maria José Brabo; 11) Relações de produção em Tomé-Açu - Responsável — Isolda da Silveira; 12) Aspectos econômicos e sociais do campesinato no Nordeste Paraense - Responsável - Lourdes Furtado; e 13) Hábitos alimentares nas regiões bragantina e do salgado - Res. ponsável - Arian Nery. 


\section{SUMMARY}

This article focuses on the anthropological studies undertaken at the Museu Paraense Emílio Goeldi, principly after the signing of the bilateral agreement between the Museu and the Instituto Nacional de Pesquisas da Amazônia (INPA) in 1954. The following topics are treated: (1) historical background, (2) periodo of the present association between the Museu and INPA, (3) objectives at the studies, (4) results obtained to date, (5) teaching and the orientation of students, and (6) current research projects.

\section{REFERENCIAS BIBLIOGRAFICAS}

ALVES, Isidoro

1978 - As entidades sobrenaturais na cosmologia Desana. T.D.I. Rev. Ass. Regional Soc Belém, (3): 1-31.

1980 - O Carnaval Devoto: um estudo sobre a Festa de Nazaré. Petrópolis, Vozes. 110 p. 7 gráficos.

ARNAUD, Expedito

1963 - A terminologia do parentesco dos índios Asurini. Rev. Mus. Paul, n. ser., São Paulo, 14: 105-19.

1968a - O parentesco entre os índios Galibi do rio Oiapoque. B. Mus. Pa. Emílio Goeldi, n. ser., Antrop., Belém, 33. 11 p. il.

1968 - Referências sobre o sistema de parentesco dos índios Palikúr. B. Mus. Pa. Emílio Goeldi, n. ser., Antrop., Belém, 36. 21 p. il,

1969 - Os índios da regiāo de Uaçá (Oiapoque) e a proteção oficial brasileira. B. Mus. Pa. Emílio Goeldi, n. ser. Antrop., Belém, 40 37 p. il. mapa.

1970 - O xamanismo entre os índios da regiāo do Uaçá - Oiapoque. Ter. Amapá. B. Mus. Pa. Emílio Goeldi, n. ser., Antrop., Belém, 44. 22 p. il.

1971 - A ação indigenista no sul do Pará, 19401970. B. Mus. Pa. Emílio Goeldi, n. ser., Antrop., Belém, 49. 25 p.

1973 - Aspectos da legislação sobre os índios do Brasil. Publ. Avulsas Mus. Pa. Emilio Goeldi, Belém, 22. 45 p.

1975a- Os índios Mundurukú e o Serviço de Proteção aos Indios. B. Mus. Pa. Emilio Goeldi, n. ser., Antrop., Belém, 54. 60 p.

1975b- Os indios Gaviōes de Oeste - Pacificação e integração. Publ. Avulsas Mus. Pa. Emilio Goeldi, Belém, 28. 85 p. il.

ARNAUD, Expedito \& ALVES, Ana Rita

1975 - A terminologia de parentesco entre os indios Galibí e outros grupos Karib. B. Mus. Pa. Emilio Goeldi, n. ser., Antrop., Belém, 60. 18 p. il.
ARNAUD, Expedito; CORTEZ, Roberto; ALVES, Ana Rita 1976 - A terminologia de parentesco dos indios Gaviōes de Oeste, Parkateyê - Tocantins, B. Mus. Pa. Emilio Goeldi, n. ser., Antrop., Belém, 63. $15 \mathrm{p}$. il.

BRABO, Maria José

1979 - Os roceiros de Muanã. Publ. Avulsas Mus. Pa. Emílio Goeldi, Belém, 32. 68 p. il.

CAVALCANTE, Paulo \& FRIKEL, Protásio

1973 - A Farmacopéia Tiriyó - Estudo Etno-botânico. Publ. Avulsas Mus. Pa, Emílio Goeldi, Belém, 24. 145 p. il.

CORTEZ, Roberto

1975 - Diálogo cerimonial e diálogo entre os Tiriyó. B. Mus. Pa. Emilio Goeldi, n. ser., Antrop., Belém, 61. 25 p.

1977 - O diaconato indigena: articulação étnica no recôncavo do Tumucumaque. Rio de Janeiro, Museu Nacional. 154 p. (Dissertação de Mestrado).

DINIZ, Edson Soares

1965 - Breves notas sobre o sistema de parentesco Makuxi. B. Mus. Pa. Emilio Goeldi, n. ser. Antrop., Belém, 31. 31 p. il.

1968 - A terminologia de parentesco dos índios Wapitxána. B. Mus. Pa. Emilio Goeldi, n. ser., Antrop., Belém, 34. 11 p. il.

1972 - Os indios Makuxi do Roraima - Sua instalação na sociedade nacional. Marilia, SP 181 p. il.

FIGUEIREDO, Napoleão

1961 - A festa dos coletores entre os Aramagoto. B. Mus. Pa. Emílio Goeldi, n. ser., Antrop., Belém, 15. 19 p. il.

FIGUEIREDO, Napoleāo \& RODRIGUES, Ivelise

1973 - As coleçōes etnográficas em Belém. In: SIMŌES, Mário F. O Museu no ano do Ses. quicentenário. Publ. Avulsas Mus. Pa. Emilio Goeldi, Bslém, 20. p. 143-61.

FRIKEL, Protásio

1959 - Agricultura dos índios Mundurukú. B. Mus. Pa. Emílio Goeldi, n. ser., Antrop., Belém, 4. 36 p. il.

1961a - Mori - A festa do rapé. Indios Kachúyana; rio Trombetas. B. Mus. Pa. Emílio Goeldi, n. ser., Antrop., Belém, 12. 34 p. il.

1961b- Onematuipe - Os transformados. B. Mus. Pa. Emilio Goeldi, n. ser., Antrop., Belém, 17. 15 p. il.

1968 - Os Xikrin. Equipamento e técnicas de sub. sistência. Publ. Avulsas Mus. Pa. Emilio Goeldi, Belém, 7, 119 p. 11.

1969/72 - Migração, guerra e sobrevivência Suiá. Rev. Antrop., São Paulo, 17/20 (1): 105-36. il.

1970 - Os Kaxúyana; notas etno-históricas. Publ. Avulsas Mus. Pa. Emílio Goeldi, Belém, 14. 82 p. il. 
1971 - Dez anos de aculturação Tiriyó (1960-70) Publ. Avulsas Mus. Pa. Emilio Goeldi, Belém, 16. 112 p. il.

1973 - Os Tiriyó - Seu sistema adaptativo. Hannover, Druck Munstermann - Druck KG. 323 p. il.

FRIKEL, Protásio \& CORTEZ, Roberto

1972 - Elementos demográficos do Alto Paru, Tumucumaque brasileiro. Indios Ewarhoyána, Kaxúyana e Tiriyó. Publ. Avulsas. Mus. Pa. Emílio Goeldi, Belém, 19. 103 p. il.

FURTADO, Lourdes de Fátima

1980 - Curralistas e redeiros de Marudá: pescadores do litoral do Pará. São Paulo, USP. 364 p. il. mimeog. (Dissertação de Mestrado).

GALVÃO, Eduardo

1959 - Aculturação indigena no Rio Negro. B. Mus. Pa. Emílio Goeldi, n. ser. Antrop., Belém. 7. 60 p. il.

1960 - Areas culturais indigenas do Brasil; 1900 . 1959. B. Mus. Pa. Emilio Goeldi, n. ser. Antrop., Belém, 8. 41 p. mapas.

1963 - Elementos básicos da horticultura de subsistência indigena. Rev. Mus. Paul., n. ser., São Paulo, 14: 120-44.

1978 - Exposiçōes de Antropologia. Belém, Museu Paraense Emílio Goeldi. 64 p. il. (Série Guias, 1).

GALVÃO, Eduardo \& SIMOES, Mário

1972 - Mudança e sobrevivência no Alto Xingu. Brasil Central. In: SCHADEN, Egon. Homem, Cultura e Sociedade no Brasil. Petró polis, Vozes. p. 183-208.

MIGLIAZZA, Ernesto

1965a- Fonologia Maku. B. Mus. Pa. Emílio Goeldi, n. ser. Antrop., Belém, 25. 17 p. mapa.

1965b- Notas fonológicas da língua Tiriyó. B. Mus. Pa. Emílio Goeldi, n. ser., Antrop., Belém. 29. 13 p.

1967 - Grupos lingüisticos do Território Federal de Roraima. In: SIMPOSIO SOBRE A BIOTA AMAZONICA, Rio de Janeiro. Atas... v. 2 Antropologia. p. 153-93. mapas

MOREIRA NETO, C.A.

1959 - Relatório sobre a situação atual dos índios Kayapó. Rev. Antrop., São Paulo, 7 (1/2): 49-64.

1960 - A cultura pastoril do Pau-D'Arco. B. Mus Pa. Emlio Goeldi, n. ser. Antrop., Belém, 10. 112 p. il.
OLIVEIRA, Adélia Engrácia de

1970a- Os índios Juruna do Alto Xingu. Dédalo, São Paulo, 11/12: 1-292. il.

1970b- Parentesco Juruna. B. Mus. Pa. Emilio Goeldi, n. ser. Antrop., Belém, 45.44 p. il.

1975a- A terminologia de parentesco Baniwa. B. Mus. Pa. Emilio Goeldi, n. ser. Antrop., Belém, 56. 34 p. il.

1975b— São João - Povoado do rio Negro (1972). B. Mus. Pa. Emílio Goeldi, n. ser., Antrop., Belém, 58.56 p. il.

1976 - Situaçāo do indígena da Amazônia: as atitudes ideais e reais da ação protecionista e da colonização. TDI Rev. Assoc. Regional Soc., Belém, (1): 14-30

1978 - A terminologia de parentesco Mura-Pirahá. B. Mus. Pa. Emílio Goeldi, n. ser., Antrop., Belém, 66. 33 p. il.

OLIVEIRA, Adélia Engrácia \& SALZANO, F.M.

1969 - Genetic implications of the demography of Brasilian Juruna indians. Soc. Biol. Univ. Chicago 16 (3).

PODRIGUES, Ivelise \& OLIVEIRA, Adélia E. de 1977 - Alguns aspectos da ergologia Mura-Pirahă B. Mus. Pa. Emílio Goeldi, n. ser., Antrop., Belém, 65. $47 \mathrm{p}$. il

SILVA, Armando Bordalo da

1959 - Contribuição ao estudo do folclore amazônico na zona bragantina. B. Mus. Pa. Emi. lio Goeldi, n. ser. Antrop., Belém, 5. 76 p. il.

SILVEIRA, Isolda Maciel da

1979 - Quatipuru - Agricultores, pescadores e coletores em uma vila amazônica. Publ. Avulsas Mus. Pa. Emílio Goeldi, Belém, 34 82 p. il.

VELTHEM, Lucia $H$. van

1975 - Plumária Tukano. Uma tentativa da análise. B. Mus. Pa. Emílio Goeldi, n. ser Antrop., Belém, 57. 29 p. il.

1976 - Representações gráficas Wayana-Aparaí B. Mus. Pa. Emilio Goeldi, n. ser. Antrop, Belém, 64. 19 p.

1980 - O parque indigena de Tumucumaque. B. Mus. Pa. Emilio Goeldi, n. ser. Antrop., Belém, 76. 31 p. mapa.

WALLACE, Ruth

1970 - Notas fonológicas da língua Kaxuyâna. B. Mius. Pa. Emílio Goeldi, n. ser. Antrop., Belém, 43, $20 \mathrm{p}$ 